\title{
Sustainability in the Built Environment: Integrating Scales of Action and Evaluation
}

\author{
Valeria Monno $^{1}$, Emilia Conte ${ }^{1}$
}

\begin{abstract}
Urban sustainability is still far from being reached. This situation testifies the difficulties to plan, design, implement and manage sustainable development processes in an integrative perspective. There are several cognitive, political and technological challenges to be faced in order to change this situation and make sustainabilisation process of the city more effective. In this paper we focus on issues concerning our ability to learn to integrate social, economic and environmental aspects through evaluation of sustainability in the city. To oppose the inconsistency of action shown by the weak results we have obtained from our investments in sustainable development during last decades, this paper argues that we need to think about sustainability of the built environment and its evaluation taking into account spatial issues, usually underestimated or assimilated to a problem of scale in the current evaluation frameworks. Following the results obtained in relation to the construction of an integrated urban-building evaluation framework, the paper underlines that if approached as spatially sensitive, evaluation of sustainability carried out at any scale would be aimed at stimulating the regenerative capacity of places.
\end{abstract}

Keywords: Built environment; Regenerative Development; Spatial Sustainability; Integrated Evaluation

\section{Introduction}

Cities and regions are daily engaged in planning, designing, implementing and managing sustainable development processes. And yet urban sustainability is far from being reached. The weak results obtained from our investments in sustainable development during last decades are due to the inconsistency of the action. This last depends on cognitive, political and technological challenges to be faced in order to change this situation and make sustainabilisation process of the city more effective. The search for coordinating better local and global policies, substantially improving governance processes either in terms of democracy and learning to develop new approaches and methods to integrate social, economic and environmental dimensions of sustainability is considered as the most urgent.

In this paper we focus on issues concerning our ability to learn to integrate social, economic and environmental aspects through evaluation of sustainability in the city.

Evaluation systems of sustainability in the city are now a common means of communications between actors involved in the building, urban and regional development processes to promote sustainable development. But, such systems risk to be instrumentally used by the market for profit because of their approach which does not substantially help to integrate social, economic and environmental dimensions of sustainability.

In order to oppose this situation, we need to think about sustainability in the built environment and its evaluation taking into account spatial issues, which in the current evaluation frameworks tend to be either underestimated or assimilated to a problem of scale. Following the results obtained in relation to the construction of an integrated urban-building evaluation framework, the paper underlines that if approached as spatially sensitive, evaluation and assessment of 
sustainability carried out at any scale would be aimed at stimulating the regenerative capacity (Rees, 2012) of places.

This paper is divided into five parts. After the introduction, the second section deals with the inconsistency of the action in the sustainable city in relation to issues concerning evaluation as an integrative tool and with the limits shown by approaches used in evaluation. The third section highlights the absence of spatial concerns in sustainability evaluation, which determines the ineffectiveness of sustainability implementation in the built environment. The fourth section proposes a spatially sensitive method of conceptualisation and evaluation of a sustainable built environment. The fifth section discusses the major implications deriving from the urban-building integrated evaluation approach proposed, particularly if compared with existing methods. Conclusions recall the urgent need for an integrative perspective in sustainability evaluation and the responsible involvement of all the actors in implementing a regenerative development.

\section{The inconsistence of action and limits of evaluation in the sustainable city}

Several limiting factors can be easily mentioned when thinking about the evaluation of sustainability in the city in relation to the inconsistency of action. Besides recurrent issues concerning the democracy of the process (Fisher, 2000), one of the most relevant is a consequence of the idea of sustainability as an integrative process of the economic, environmental and social dimensions of development (Davidson et al., 2012).

It is almost impossible to exactly define the meaning of sustainable development and what sustainability requires in order to be turned into reality in an urban environment. However, despite such an ambiguity (Gunder, 2006; Campbell, 1996), sustainability in the city evokes a conception of life and development shaped by harmonious interrelations among society, economy and environment (Redclift, 2005). Sustainable development goes further the idea of facing the complexity of environmental problems caused by the illusion of an unlimited economic growth. It shows the necessity of integrating economic, social and environmental factors in any hypothesis of human intervention. However, how to integrate these factors within and among different scales and plans of action -projects, plans, policies- has become one of the utmost challenges to be faced in order to implement sustainability (Buhrs, 2009). Despite the enormous amount of cognitive and political investments which have been channelled in this direction, integration is still in its infancy. Consequently, the lack of integration is considered one of the causes underlying the inconsistency of action.

Difficulties in fulfilling integration are particularly evident in the field of evaluation systems of sustainability in the city. If, on the one hand, cultural, cognitive, political and institutional barriers slow the process, on the other hand, the search for integration through evaluation has also shown several flaws and gaps in the ways of conceiving and implementing it. Flaws and gaps are usually ascribed to the silo approach (Davidson et al., 2012), where environment, economy and society remain detached dimensions of action and evaluation. This favours a prevailing tendency to include environmental concerns into the economic development and discourages the analysis of their reciprocal interdependences.

As a result, the silo approach has favoured a process of ecological modernisation rather than a radical change of economic processes aimed at growth. At the same time, social aspects have been systematically and broadly undervalued when compared to environmental and economic issues. Thus, the evaluation of sustainability does not often match social justice criteria (Walker, 2010). Reciprocally, economic integration in environmental policy remains largely unpractised in theory as well as in practice (Tosun \& Knill, 2009).

In order to smooth these problems, collaborative approaches have been used to open up evaluation to the dialogue among different value systems with the aim to trigger integrative 
processes. Yet, limited institutional capabilities and problems related to issues of democracy such as asymmetric power relationships and search for consensus have undermined the potentialities of governance processes both in terms of generation of new sustainable knowledge and integration among conflicting values.

Against such a perspective, critics have highlighted that the idea to integrate environment, economy and society to achieve an imagined harmonic sustainable future is misleading. It is increasingly clear that, in reality, these three dimensions of development are not disconnected at all. Because of this, they could never reach a harmonic development, at least under the current economic regimes. In the absence of a more realistic and political understanding concerning how economy, environment and society interact, the search for integrative actions among these dimensions diverts the reasoning on evaluation of sustainability from the process of city production towards a continuous search for new and better indicators (Davidson et al., 2012). In order to oppose such reductionist reasoning, a socio-ecological perspective should be used to conceptualise the relationships between the built environment and natural environments.

The environmental crisis and the impacts of climate change on urban environment have also highlighted other crucial limits of existing evaluation systems. A new concern towards resilience (Folke, 2006) induces to reconsider sustainability and its evaluation following the logic of adaptive change. Rather than using deterministic and linear dynamics of change, evaluation should include adaptive capacities of urban environments and ecosystems and the related dynamics under external and internal stresses and disturbances that threaten their balance, stability and cohesion (Folke, 2006). Furthermore, if resilience becomes a fundamental quality of self-regenerating systems then evaluation has to recalibrate its focus on minimisation of impacts by including actions aimed at the regeneration of pre-existing critical environmental situations.

The above synthetic review concerning the limits of existing approaches to evaluation of the sustainability in the city shows that, although these systems have contributed to sustainability in the city by minimising impacts of human interventions on ecosystems and helped to preserve as much as possible resources and the equilibrium of ecological dynamics, they need to be revised in order to be able to face the challenges of implementing sustainability in the city.

\section{The absence of spatial concerns}

From our point of view, a way to face effectively the challenge of integration implies reintroducing unsolved spatial issues in the sustainability evaluation discourse and practice.

The absence of spatial concerns within the evaluation can be easily detected. The evaluation of the sustainability in the city suffers from the fact that sustainability was thought for saving our planet and not the city taking a long-range perspective on the dynamics of change. The need of sustainability in the city emerged as a new horizon for urban development only when it was clear that the human life on the planet would abandon rural forms in favour of urban life. Thus, the evaluation of urban sustainability has been usually linked to the necessity to find immediate solutions to crucial global problems through the reduction of impacts produced by local urban transformations on wider ecosystems or their networks (Forman, 1997; Elmqvist et al., 2013). As a result, a scalar rather than spatial reasoning characterises the scenario of sustainability evaluation systems.

We have defined the different perspectives in reasoning about building and urban sustainability respectively as buildingcentric (Conte \& Monno, 2012) and urbancentric approaches.

The buildingcentric approach looks at the building as an object in which to add several 'sustainable' design choices, in order to pursue a good rate in the assessment system related to the evaluation method chosen (Giama \& Papadopoulos, 2012). Then the designing activity is mainly driven by performances expressed by the building (Guy, 2010), measured by means of sustainability indexes 
and indicators as used in the assessment system. In the search for the most rewarding choice in terms of sustainable performances of the building, architects and engineers are at risk of losing the vision of the building as a whole system, as the design process goes on (Magent et al., 2009). Therefore, on one hand the sustainable building evaluation and assessment systems have promoted the process of shifting a general and theoretical idea of sustainability into the building practice. On the other hand, they can be seen as one of the reasons for the inconsistency of the action expressed at the building scale, since the behaviour of a sustainable building as a whole system does not correspond to a mere addition of separate sustainable performances of its subsystems or parts.

The urbancentric approach looks at an urban context, which can be the entire city or a portion of it variously sized -a site/community/neighbourhood-, generally regarded as a homogeneous whole to evaluate in terms of overall environmental impact. To measure the impacts, many different indexes and indicators together with assessment systems have been developed during years (Sharifi \& Murayama, 2013). However, they currently depict a fragmented scenario both in nature and issues involved; therefore, choosing among them, privileging one or the other depends on the objective of the evaluation and the detail of the assessment. Consequently, when a systemic vision is used for evaluating an urban context it remains bound to the specific application.

Moreover, since none of the theories used so far is able to give elements to interpret and evaluate urban sustainability considering the character of urban nature, cities have been often evaluated as disconnected from their own environment and instead inserted in external networks. Besides being part of global and local ecosystems and exchange circles of energy and matter, cities are socio-ecological systems whose nature and ecological dynamics are profoundly different from those characterising the ecosystems outside of it. As a result, the sustainability of cities and their ecological dynamics are endangered (Mrak, 2013).

Therefore, current evaluation methods mainly focus on a component of a system and the scale of application determines the purpose of the evaluation: on one level, at the bottom, there are individual sustainable buildings; on another level, at the top, there are sustainable sites/communities/neighbourhoods/cities. But, separating the scales influences sustainability actions reducing their global effectiveness, so this is a limiting aspect of evaluation which can be seen as one of the reasons for the inconsistency of the action.

Through a scale-centric evaluation our cities risk of becoming collections of single sustainable objects such as green and blue infrastructures, transport systems, buildings, industries, each of them designed and imagined in relation to the need of minimising impacts or restoring one or more ecological dynamics, but with no or weak relations with other objects and the city considered as whole changing ecological dynamics. As a result each of these objects lives alone inside the city and almost disconnected from the city development and impact on the environment. Furthermore, such a fragmented conception of sustainability intended as a quality of objects favours the search for the environmental quality at the expense of social and economic issues.

On the contrary, if for example we focus on a sustainable building, we need to understand how the sustainable qualities of a building and its surrounding built environment influence each other and shape a specific economic, social and environmental sustainable urban context and in which extent they exploit the local potentialities for an effective sustainable development at other scales.

\section{A spatially sensitive integrated evaluation approach}

As described in the above sections, instead of favouring integration, the evaluation of sustainability in the city privileges scale-based approaches which tend to see the city as a homogeneous whole or to splinter it in many objects, analysing and assessing their sustainability 
through detached environmental, social and economic dimensions. This makes difficult to recompose the results of an action in a coherent integrated framework which allows managing increasingly complex environmental problems by improving the sustainability in the city. Instead of considering governance as a solution to the integration problem, our evaluation approach proposes to change the socio-technical idea of the built environment underlying existing evaluation systems.

From our point of view, a way to face effectively this challenge implies reintroducing unsolved spatial issues in the sustainability evaluation discourse. This goal can be pursued by shifting evaluation process towards an assessment of the regenerative sustainability, which "implies reconnecting human aspirations and activities with the evolution of natural systems - essentially co-evolution. It means shifting human communities and economic activities back into alignment with life processes ... This is not preservation of an ecosystem, nor is it restoration. Instead, it is the continual evolution of culture in relationship to the evolution of life" (Mang \& Reed, 2012, p. 25). If the problem of integration is one of the reasons at the basis of the inconsistency of the action as descripted above, then exploiting the local potentialities for an effective sustainable development in a specific urban context means not only reducing environmental impacts or sustain the ecological resilience, but rather trigger a regenerative process of a place that catches and exploits the regenerative potentialities of the built environment, considering it a socioecological system.

The socio-ecological vision of the built environment underlying the regenerative approach can be then the way to exceed the absence of integration characterising the current approaches implemented in practice for conceptualising building and urban sustainability. Within a regenerative perspective, buildings, infrastructures, policy-makers, people using them, and the natural environment around are a whole system. Following a socio-ecological perspective the built environment is constituted by a particular assemblage of human and non-human agents which are interconnected through complex socio-ecological flows, relationships and dynamics of transformation at different scales (Moffatt \& Kohler, 2008; Pincetl, 2012). The set of flows, relationships and dynamics of transformation constitutes the metabolism (Wolman, 1965) of an urban context which defines its specific features. It is clear that in a socio-ecological perspective any object in the city is not only shaped by relationships of proximity but also by its connections with distant agents and ecological dynamics.

According to these premises and following the theory of socio-ecological system (SES) (Holling, 2001; Pincetl, 2012), our evaluation approach abandons a generic definition of sustainability as integration of the economic, environmental and social dimensions to embrace a regenerative perspective. Analogously, our evaluation approach dismisses a conceptualisation of urban space as a collection of man-made objects interacting in more or less complex ways with local ecological dynamics, or as connected just to wider ecosystem through flows of matter and energy.

In our evaluation approach sustainability in the city is a changing spatial configuration determined by a specific form of social and ecological relationships. As such, the evaluation is a way to reflect on a 'specific' form of integration among economic, social and environmental factors. In fact, in our approach integration already exists in the city and is what constitutes an unsustainable or sustainable profile of the built environment. The goal of evaluation is no longer to integrate in a more or less balanced form social, economic and environmental factors through an action, but to recognise sustainable and unsustainable relationships shaping a specific configuration of the built environment in order to understand in which ways the action under scrutiny can contribute to reorient and re-align that configuration to make it regenerative rather than destructive.

In this way, the evaluation will show the ability of the built environment to adapt to change, selfmaintaining the path towards a sustainable development during time, and promoting the continuous restructuring of environmental and socio-economic systems in relation to a 
transformative action.

\subsection{The evaluation framework for urban-building interactions}

The operative goal of our approach is to define an integrated methodological framework for the evaluation of sustainability of the built environment, rather than for a building or a neighbourhood. The framework reflects the regenerative perspective and the socio-ecological interpretation of the built environment and focuses on the urban-building interactions.

Therefore, in the evaluation framework we consider the urban context in which an agent/object is localised as the 'built environment'. This represents a specific, not necessarily continuous, space in which agents interact through a set of material and immaterial flows and relationships, both local and supralocal, i.e. the metabolism. The quality and spatial extensions of a built environment depend on these flows and relationships through which any kind of agent is interconnected. Thus, the sustainability of an existing configuration of urban space with the related urban nature has to be considered in relation to the built environment metabolism.

Consequently, sustainability of any kind of transformative action on individual agents/objects composing the built environment has to be evaluated considering the transformations (including alterations of the adaptive capacity) which it activates in the built environment. Making sustainable an agent/object has to imply the regenerative re-orientation and re-alignment of the relationships between it and the built environment so exploiting the regenerative potential of an action. In our approach, such a potential and consequently the sustainability of an action are related to the concept of regenerative development which include resilience, regeneration and adaptation; since vulnerability and resilience are complementary parameters, resilience can be appreciated through a variation of vulnerability. Following Adger (2006), in our framework vulnerability is defined as the susceptibility of the built environment with respects to harms produced from agents, flows and relationships. Therefore variations of vulnerability, adaptation and regeneration of the built environment come to represent the regenerative quality and the direction of change under scrutiny. Through correlating these variations we can appreciate in which ways and extent an action stimulates potential adaptations and regenerations in the urban context and if these move the built environment towards regenerative capacities.

The built environment vulnerability is described through categories of analysis related to its metabolism: structures, flows, environmental quality, and lifestyles. These categories are the background against which the sustainability of a building has to be evaluated and they define the conditions to detect the effective regenerative capacity of a sustainable building (Figure 1). Buildings are seen as complex systems which interact with the built environment metabolism through their performances: site, indoor and outdoor environment, operation and technical design.

Figure 1. The integrated urban-building evaluation framework
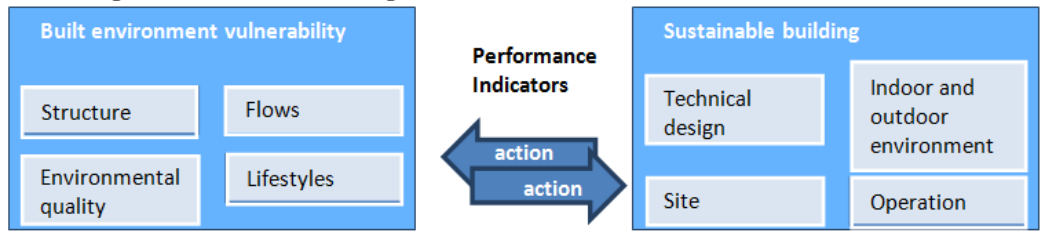

Being an agent, the building alters the metabolism of the built environment through its own performances thus reducing or increasing the built environment vulnerability. Although still considered, environmental impacts and pressures produced by a building have to be related and reinterpreted as disturbances and perturbations causing variations of vulnerability of the built 
environment. Thus, the framework measures the contribution of a building to the sustainability of a built environment as an induced shift away from its current vulnerability. The direction of change induced on the metabolism signals the regenerative potential.

To express the direction of a regenerative process, the framework uses qualitative rather than quantitative holistic indicators; they are intended to measure the regenerative potential of an action representing the multiple aspects and dimensions of sustainability (Figure 2).

Figure 2. The regenerative perspective on evaluation

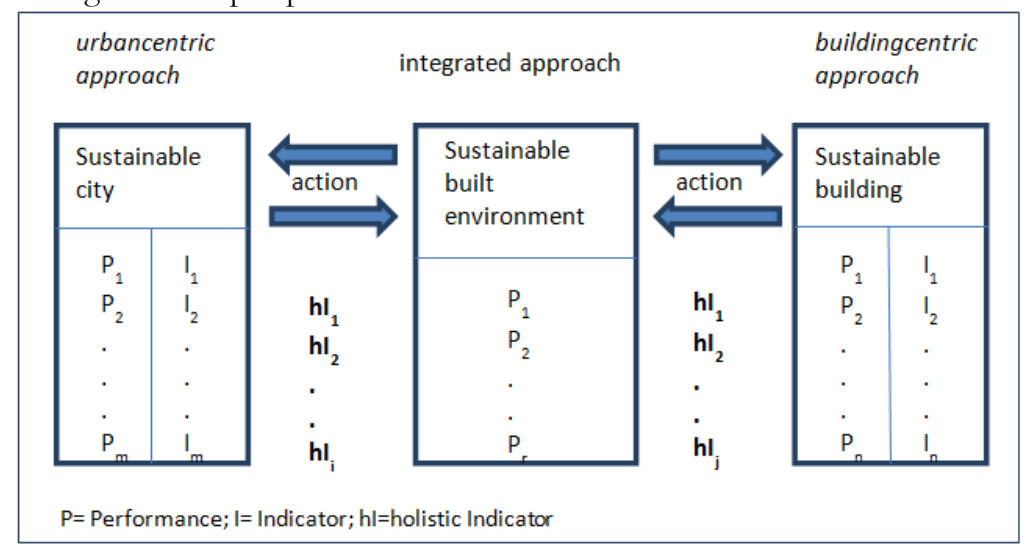

\section{Discussion}

Overcoming limits of the current evaluation systems related to their underlying scalecentric perspective, linear conception of time and an archaic vision of integration, our regenerative and SES-based approach is spatially sensitive and helps to consider contemporarily the social, economic and environmental dimensions of sustainability.

To summarise, the main differences between our approach to evaluation and the existing ones are synthesised in Table 1.

Table 1. Main differences between existing evaluation methods and our approach

\begin{tabular}{|l|l|l|}
\hline TIME & CURRENT & INTEGRATED \\
\hline SPACE & Present, static equilibrium & Adaptive, dynamic \\
\hline $\begin{array}{l}\text { Scale based } \\
\text { CHASPECTIVE }\end{array}$ & $\begin{array}{l}\text { Sustainability - Integrating } \\
\text { environment/economy }\end{array}$ & $\begin{array}{l}\text { Urban matrix - Assemblage of } \\
\text { Relations, flows, agent }\end{array}$ \\
\hline $\begin{array}{l}\text { CATEGORIES OF } \\
\text { ANALYSIS }\end{array}$ & $\begin{array}{l}\text { Economicinality - } \\
\text { Reorienting current forms of } \\
\text { integration crystallized in agents }\end{array}$ \\
\hline
\end{tabular}

There is a substantial implication of this approach in carrying out the sustainability evaluation of an agent composing the built environment: our evaluation blurs the separation between the scale of the agent and the urban scale. The urban space is not a dead background for the agent; in fact, an agent has to be evaluated through those qualities which interact with the built environment and its metabolism. Therefore, what is at stake in our evaluation approach is the spatial quality of the built environment which is inseparably connected to the built environment potentialities and regenerative capacities. 
The integrated urban-building evaluation framework confirms that our approach is integrative. The assumption that the integration already exists within objects and the built environment imposes to constantly maintain an integrated perspective among economic, social and environmental dimensions rather than focus on each of them. In fact, since the framework aims at identifying and qualifying regenerative potentialities and capacities, the evaluation focus is constantly on the interactions among economic, environmental and social relationships and flows connecting an agent and the built environment.

In addition to this, the evaluation framework shows that our spatially sensitive approach radically restructures existing evaluation because it:

- focuses on action and its implications at different scales; it helps to contextualise the action without disconnecting it from proximate and distant spatial relations;

- considers actions in a co-evolutionary and spatial perspective on the built environment transformations thus requiring an integrated appreciation of any action;

- grasps the regenerative interactions between buildings and the built environment through the ability of an action to stimulate the resilient and adaptive capacity of a context;

- shows potentialities of actions directed towards a regenerative development;

- helps to involve a wider array of actors only rarely considered in the evaluation process.

A comparison between the result obtained through our framework and existing evaluation frameworks contributes to show what is missing in them (Conte \& Monno, 2012). It is clear that our evaluation approach does not only help to evaluate the sustainability of a building intended as a producer of environmental pressures, but it also challenges the dominant conceptualisation of what is a sustainable building and what constitutes its contribution to the sustainability of the urban context in which it is situated. For this reasons it invites us to use new conceptual tools and implies to apply new ways of acting: on both levels, it stimulates innovation and experimentation, challenging our knowledge and current technologies (de Vries \& Peterson, 2009), particularly those fielded and used in recent decades in an attempt to move toward a sustainable development.

\section{Conclusions}

Evaluation methods and assessment systems can be criticised, but the present situation shows that they are increasingly used, promoted by the market as well as by policy for several reasons. For that, as already stated, they are now a common means of communications between actors involved in the building and urban development processes. At the same time, their limited efficacy in opposing the inconsistency of action suggests a profound revision of their substantive premises. Why not use them as a tool to guide the change required by the regenerative approach, proceeding in practice in parallel to the theoretical definition (Robinson \& Cole, 2015)?

A way to succeed, it is argued, must look at overcoming the fragmentation characterising the action, both in time and in places, through empowering the cooperation between actors -political, economic, social- involved in sustainable processes (Hedlund-de Witt, 2014). From our point of view, besides problems concerning governance as a way to face effectively the challenge of integration, we need to reintroduce in the sustainability discourse and its evaluation unsolved crucial issues of spatial integration. In particular, we suggest to move the focus of evaluation from the objects to the built environment in order to make effective sustainability in the city trying to change current sustainability evaluation frameworks usually aimed at integrating environmental concerns in a specific plan or project.

In this paper, we propose an approach to sustainability evaluation based on the SES theory and aimed at grasping the resilient interactions between buildings and the urban space. Its goal is to identify possible ways to satisfy the urgent need for an integrated methodological framework for sustainability evaluation. Drawing on the causes underlying the inefficacy of evaluation in dealing 
with the inconsistency of action as described in the sections above, we have structured an integrated urban-building evaluation framework. In order to overcome the archaic vision of integration, our approach adopts a spatially sensitive perspective which shifts the attention from the concept of impact to that of regenerative sustainability. Our evaluation framework can help to stimulate the actors of the process to the cultural change that the regenerative approach requires (du Plessis, 2012) addressing their responsibilities on the coherence and effectiveness of the action.

\section{References}

Adger, W. N. (2006). Vulnerability. Global Environmental Change, 16(3), 268-281.

Buhrs, T. (2009). Environmental Integration: Our Common Challenge, New York, USA: Sunny Press.

Campbell, S. (1996). Green Cities, Growing Cities, Just Cities?: Urban Planning and the Contradictions of Sustainable Development. Journal of the American Planning Association, 62(3), 296-312.

Conte, E., \& Monno, V. (2012, April). Beyond the buildingcentric approach: A vision for an integrated evaluation of sustainable buildings. Environmental Impact Assessment Review, 34, 31-40.

Davidson, K. M., Kellett, J., Wilson, L., \& Pullen, S. (2012). Assessing urban sustainability from a social democratic perspective: a thematic approach. Local Environment: The International Journal of Justice and Sustainability, 17(1), 57-73.

de Vries, B. J. M., \& Peterson, A. C. (2009). Conceptualizing sustainable development. An assessment methodology connecting values, knowledge, worldviews and scenarios. Ecological Economics, 68(4), 1006-1019.

Du Plessis, C. (2012). Towards a regenerative paradigm for the built environment. Building Research \& Information, 40(1), 7-22.

Elmqvist, T., Redman, C. L., Barthel, S., \& Costanza, R. (2013). History of urbanization and the missing ecology. In T. Elmqvist, M. Fragkias, J. Goodness, B. Güneralp, P. J. Marcotullio, R. I. McDonald, S. Parnell, M. Schewenius, M. Sendstad, K. C. Seto, \& C. Wilkinson (Eds.), Urbaniz̨ation, Biodiversity and Ecosystem Services: Challenges and Opportunities (pp. 13-30). Dordrecht, Heidelberg, New York, London: Springer.

Fisher, F. (2000). Citizens, Experts, and the Environment: The Politics of Local Knowledge. Durham, NC, USA: Duke University Press.

Folke, C. (2006). Resilience: the emergence of a perspective for social-ecological systems analyses. Global Environmental Change, 16(3), 253-67.

Forman, R. T. T. (1997). Land mosaics. Boston, MA: Cambridge University Press.

Giama, E., \& Papadopoulos, A. M. (2012) Sustainable building Management: overview of certification schemes and standards. Advances in Building Energy Research, 6(2), 242-258.

Gunder, M. (2006). Sustainability. Planning's saving grace or road to perdition? Journal of Planning Education and Research, 26(2), 208-221.

Guy, S. (2010). Pragmatic ecologies: situating sustainable building. Architectural Science Review, 53(1), 21-28.

Hedlund-de Witt, A. (2014). Rethinking Sustainable Development: Considering How Different Worldviews Envision "Development" and "Quality of Life". Sustainability, 6(11), 8310-8328. doi:10.3390/su6118310.

Holling, C. S. (2001). Understanding the complexity of economic, ecological, and social systems. Ecosystems, 4(5), 390-405.

Magent, C. S., Korkmaz, S., Klotz, L. E., \& Riley, D. R. (2009). A Design Process Evaluation Method for Sustainable Buildings. Architectural Engineering and Design Management, 5(1-2), 62-74.

Mang, P., \& Reed, B. (2012). Designing from place: a regenerative framework and methodology. Building Research \& Information, 40(1), 23-38.

Moffatt, S., \& Kohler, N. (2008). Conceptualizing the built environment as a social-ecological system. Building Research \& Information, 6(3), 248-268.

Mrak, I. (2013). Locally Based Development-Tools for Identifying Opportunities and Evaluating Port Area Strategies of Rijeka. Sustainability, 5(special Issue), 4024-4056.

Pincetl, S. (2012). Nature, urban development and sustainability - What new elements are needed for a more comprehensive understanding? Cities, 29(supplement 2), 32-37. 
Redclift, M. (2005). Sustainable development (1987-2005): an oxymoron comes of age. Sustainable Development, 13(4), 212-227.

Rees, W. E. (2012). Cities as Dissipative Structures: Global Change and the Vulnerability of Urban Civilization. In M. P. Weinstein, \& R. E. Turner (Eds.). Sustainability Science (pp. 247-273). Dordrecht, Heidelberg, New York, London: Springer.

Robinson, J., \& Cole, R. J. (2015). Theoretical underpinnings of regenerative sustainability. Building Research \& Information, 43(2), 133-143.

Sharifi, A., \& Murayama, A. (2013, January). A critical review of seven selected neighborhood sustainability assessment tools. Environmental Impact Assessment Review, 38, 73-87.

Tosun, J., \& Knill, C. (2009). Economy and Sustainability-How Economic Integration Stimulates Stringent Environmental Regulations. Sustainability, 1(4), 1305-1322. doi:10.3390/su1041305.

Walker, G. (2010). Environmental justice, impact assessment and the politics of knowledge: The implications of assessing the social distribution of environmental outcomes. Environmental Impact Assessment Review, 30(5), 312-318.

Wolman, A. (1964). The metabolism of cities. Scientific American, 213(3), 179-190. 